\title{
Uso de matéria seca de cará e de mandioquinha-salsa na composição da ração para frangos de corte.
}

\author{
Maria do Carmo Vieira1; Néstor A. Heredia Z. ${ }^{1,2}$; João Dimas Graciano'; Rosilene Antonio Ribeiro ${ }^{3}$ \\ ${ }^{1}$ UFMS - DCA, C. Postal 533, 79804-970 Dourados - MS.
}

\begin{abstract}
RESUMO
O trabalho foi desenvolvido no aviário experimental localizado na horta do Núcleo Experimental de Ciências Agrárias (NCA) da UFMS, em Dourados - MS, entre 21 de fevereiro e 3 de abril de 1997. Foram estudadas quatro fórmulas de ração para alimentação de frangos de corte, sendo elas: $\mathbf{1}$ - 30\% ração concentrada (RC) + $70 \%$ milho $(\mathrm{M}) ; 2-30 \% \mathrm{RC}+15 \%$ matéria seca de cará $+55 \% \mathrm{M}$; $3-30 \% \mathrm{RC}+15 \%$ matéria seca de resíduos de mandioquinha-salsa $+55 \% \mathrm{M}$ e $4-30 \% \mathrm{RC}+30 \%$ matéria seca de cará $+40 \% \mathrm{M}$. A unidade experimental foi uma ave e os tratamentos arranjados no delineamento experimental de blocos casualizados, com dez repetições. As matérias secas de cará (mistura de rizomas e tubérculos) e dos resíduos de mandioquinha-salsa (rebentos, coroas e raízes nãocomercializáveis) foram obtidas de plantas propagadas na horta do NCA-UFMS e secadas ao sol, em terreiro cimentado. As aves foram pesadas aos 7, 14, 21, 28, 35 e 42 dias após o início do experimento. As curvas de pesos médios dos frangos foram características para a espécie e as taxas de crescimento foram significativamente dependentes dos tratamentos. Os frangos alimentados com a ração 3 apresentaram peso médio final de $2.113,7 \mathrm{~g}$ e conversão alimentar de $2,1186 \mathrm{~kg}$ de ração/ $\mathrm{kg}$ de peso do frango, que foi inferior em $2,2 \% ; 9,7 \%$ e $23,9 \%$ quando comparada com as dos frangos alimentados com as rações 1, 2 e 4, respectivamente. A maior quantidade de carne a ser realmente consumida - cozida ou assada (com custo/ $\mathrm{kg}$ de $\mathrm{R} \$ 0,7158$ e $\mathrm{R} \$ 0,9825$, respectivamente) - foi dos frangos criados com a ração 3 . Os frangos alimentados com ração contendo resíduos de mandioquinha-salsa ou cará apresentaram sabor de frango caipira e baixo teor de gordura.
\end{abstract}

Palavras-chave: Dioscorea $s p$, Arracacia xanthorrhiza, resíduos vegetais, alimentação de aves, custos.

\begin{abstract}
Yam and Peruvian carrot dry matter use in ration composition for broiler feed.

An experiment was carried out in the experimental aviary at the Farmer Science Experimental Center - NCA of the Federal University of Mato Grosso do Sul (UFMS) in Dourados-MS between February $21^{\text {st }}$ and April $3^{\text {rd }}, 1997$. The following ration formulas for broiler feed were studied: $\mathbf{1}-30 \%$ concentrated ration $(\mathrm{CR})+70 \%$ corn (C); 2 - 30\% CR + 15\% yam dry matter $+55 \% \mathrm{C} ; \mathbf{3}-30 \% \mathrm{CR}+15 \%$ Peruvian carrot dry matter $+55 \%$ C $; 4-30 \%$ CR $+30 \%$ yam dry matter $+40 \% \mathrm{C}$. Each bird represented one experimental unit and treatments were arranged in a randomized block design, with ten replications. Yam dry matter (rhizomes and tubers) and Peruvian carrot residues (sprouts, crowns and non-commercial roots) were obtained from propagated plants at the NCA-UFMS vegetable garden and then sun dried. Birds were weighed 7, 14, 21, 28, 35 and 42 days after the beginning of the beginning of the experiment. Broiler average weight curves were characteristics to the species and growth rates were significantly dependent on treatments. Broilers fed with ration formula $3 \mathrm{had}$ an average final weight of $2.1137 \mathrm{~kg}$ and a feed conversion of $2.1186 \mathrm{~kg}$ of ration $/ \mathrm{kg}$ of broiler weight, which was $2.2 \%, 9.7 \%$ and $23.9 \%$ lower when compared with rations 1,2 and 4 , respectively. The amount of broiler meat available for consumption, broiled or roasted, (with cost $/ \mathrm{kg}$ of $\mathrm{R} \$ 0.7158$ and $\mathrm{R} \$$ 0.9825 , respectively) was greater in broilers fed with ration 3 . Comparing qualitatively taste and fat content, it was observed that those broilers fed with ration 4 had a "yokel" broiler taste and minimum fat.
\end{abstract}

Keywords: Dioscorea $s p$, Arracacia xanthorrhiza, vegetable residues, bird feed, costs.

\section{(Aceito para publicação em 07 de dezembro de 1998 )}

O crescimento da avicultura brasileira, a partir dos anos 70 , conquistou significativa participação na produção de proteína de origem animal e importante posição socioeconômica no País. No período 1970-1988, a produção anual de carne de frango evoluiu de 0,217 para 1,947 milhões de toneladas e a produção de ovos, de 0,861 para 1,24 bilhões de dúzias, ou seja, um crescimento de $797 \%$ e $44 \%$, respectivamente. O consumo per capita, naquele período, passou de 2,3 para $12,0 \mathrm{~kg}$ de frango e de 78 para 110 ovos/habitante/ano (Schmidt \&
Ávila, 1990). Observa-se portanto que é enorme o valor econômico atual da indústria avícola no Brasil, especialmente ao se considerar que ela movimenta uma série de atividades de intermediação, como a produção de matérias primas para rações, prestação de serviços e industrialização (Englert, 1980).

Os países do Terceiro Mundo desenvolvem investigações de ponta, visando solucionar problemas dos médios e grandes agropecuaristas, esquecendo-se das questões de subsistência dos pequenos agricultores. A pesquisa agrícola no
Brasil tem sido direcionada para culturas dependentes dos insumos industrializados, potencialmente poluidores e caros. Acredita-se que para mudar essa situação devem ser repensados os conceitos de produtividade e economicidade agrícola (Vieira, 1995), pois podem ser expandidas as fronteiras agrícolas abrangendo os solos menos férteis dos cerrados e irrigando os semi-áridos (Silva, 1996). Consequentemente apenas espécies de maior dinâmica fisiológica vegetal, com retenção hídrica e rusticidade às intem-

\footnotetext{
${ }^{2}$ Bolsista de Produtividade em Pesquisa-CNPq

${ }^{3}$ Estudante do curso de Mestrado em Agronomia-UFMS
} 
péries climáticas, prevalecerão, como é o caso das hortaliças chamadas alternativas ou não-convencionais, como mandioquinha-salsa (Arracacia xanthorrhiza), inhame (Colocasia esculenta) e cará (Dioscorea sp).

O Estado de Mato Grosso do Sul ainda não tem tradição no cultivo de hortaliças, praticando principalmente o monocultivo de soja e trigo, além da criação de gado de corte. Nos últimos anos, vêm aumentando as áreas de cultivo de hortaliças nos arredores das maiores cidades do Estado, o que possibilita a venda do produto diretamente ao consumidor (Vieira, 1995). Atualmente, a quantidade disponível de mandioquinha-salsa e cará, nos mercados locais, e o número de horticultores dedicados à sua exploração são pequenos, por falta de tradição no consumo pela população local e pela falta de alternativa de uso dos produtos principais e dos seus resíduos amídicos. Da mandioca por exemplo, são considerados resíduos as partes constituintes da própria planta, geradas em função do processo tecnológico adotado, assim como os restos de cultura. Tanto a qualidade quanto a quantidade dos resíduos variam bastante, em função de uma série de fatores tais como cultivar, idade da planta, tempo após a colheita, tipo e regulagem do equipamento industrial dentre outros (Cereda, 1996). Da planta de mandioquinha-salsa, podem ser usadas as raízes não-comercializáveis, as coroas e os rebentos para consumo animal (Vieira, 1995); do inhame podem ser utilizados os rizomas-mães, rizomas-filhos pequenos e refugos (Heredia \& Yamaguti, 1994); do cará, podem ser usados os rizomas não lisos, tubérculos pequenos e refugos, tanto do cará-da-costa ou caramujo quanto do cará-pezão (Heredia \& Vieira, 1994; Heredia et al., 1995).

Quanto à avicultura em Mato Grosso do Sul, apenas uma empresa administra mais de 300 aviários com 15.000 frangos de corte cada um, tendo abate de 115.000 frangos/dia, com peso médio de 2,2 kg obtidos em 49 dias, o que resulta em $253.000 \mathrm{~kg} /$ dia de frango.

Os objetivos do presente trabalho foram a diminuição dos custos e a melhoria da qualidade da carne de frango, a determinação dos melhores percentuais de cará e/ou de mandioquinha-salsa que substituam o milho na ração para frangos de corte, a melhora qualitativa da carne e a diminuição dos custos de produção, assim como o estímulo aos alunos do Curso de Agronomia da UFMS a trabalharem com cará e mandioquinha-salsa.

\section{MATERIAL E MÉTODOS}

O trabalho foi desenvolvido no aviário experimental, com capacidade para 800 aves, localizado na horta do Núcleo Experimental de Ciências Agrárias (NCA) da Universidade Federal de Mato Grosso do Sul (UFMS), em Dourados-MS, entre 21 de fevereiro e 3 de abril de 1997. Foram estudadas quatro fórmulas de ração para alimentação dos frangos de corte, sendo: 1 - 30\% de ração concentrada (RC) $+70 \%$ de milho (M); 2 - ração com $30 \% \mathrm{RC}+15 \%$ de matéria seca de cará $+55 \% \mathrm{M} ; 3$ - ração com $30 \% \mathrm{RC}+15 \%$ de matéria seca de resíduos de mandioquinha-salsa + $55 \%$ M e 4 - ração com $30 \% \mathrm{RC}+30 \%$ de matéria seca de cará $+40 \% \mathrm{M}$. A primeira formulação é a normalmente usada pelos avicultores.

Os tratamentos foram arranjados no delineamento experimental de blocos casualizados. A unidade experimental considerada foi uma ave, sorteada inicialmente aos sete dias, dentre as 80 aves que compunham o boxe (tratamento) e posteriormente marcada para determinação semanal do ganho de peso. Dentro de cada boxe foram sorteadas dez aves que, após marcadas com sinais individuais, corresponderam às repetições.

Os materiais vegetativos utilizados para as rações foram os rizomas e tubérculos do cará Caramujo e os rizomas do 'Liso' (RTC), além dos resíduos (rebentos, coroas e raízes nãocomercializáveis) de mandioquinha-salsa (RMS). Após a colheita, o material vegetativo foi cortado em fatias finas e colocado em terreiro cimentado para secagem ao sol. O material seco foi triturado e peneirado para posterior uso na mistura com a ração concentrada e com o milho, adquiridos no comércio de Dourados - MS. O preparo do formulado das rações foi feito no laboratório de campo da área Zootécnica do NCA-
UFMS. Os resultados da análise da sua composição nutritiva dos componentes das rações são apresentados na Tabela 1 .

Os pintinhos de um dia, mistura de machos e fêmeas, com peso médio de $45 \mathrm{~g}$, foram adquiridos no mercado local, sendo que na primeira semana foram alimentados com ração normal e no sétimo dia procedeu-se à pesagem geral e sorteio das 80 aves para cada tratamento. Dentre essas, sortearam-se e pesaram-se as dez que corresponderiam às repetições. Os cuidados dispensados às aves, dessa fase até o abate, foram os recomendados por Englert (1980). As aves foram pesadas aos 7, 14, 21, 28, 35 e 42 dias após o início do trabalho. Em cada época, pesou-se também a ração remanescente para obter os dados de consumo e posterior cálculo da conversão alimentar. No dia do abate foram determinados os pesos dos frangos com penas, sem penas e limpos (sem cabeça, pés e miúdos) e o teor visual de gordura, além das perdas de peso dos frangos, quando cozidos ou assados. O sabor dos frangos foi determinado através de 20 degustadores.

\section{RESULTADOS E DISCUSSÃO}

As curvas dos pesos médios dos frangos, entre um e 42 dias de idade, apresentadas na Figura 1, são características para a espécie. As taxas de crescimento foram dependentes dos tratamentos, especialmente a partir dos quatorze dias, quando os frangos alimentados com ração normal foram mais pesados $(411,4 \mathrm{~g})$ que os tratados com ração com $30 \%$ de cará $(365,9 \mathrm{~g})$, devido provavelmente à necessidade de as aves adaptarem seu metabolismo à mudança alimentar.

Os maiores pesos médios finais determinados nos frangos com penas (Tabela 2) foram para os alimentados com ração contendo resíduos de mandioquinha-salsa $(2.113,7 \mathrm{~g})$, apresentando conversão alimentar de 2,1186 $\mathrm{kg}$ de ração/kg de peso do frango, que foi inferior em $2,2 \% ; 9,7 \%$ e $23,9 \%$, quando comparados com a ração normal $(2,1646)$; ração com $15 \%$ de cará $(2,3246)$ e ração com $30 \%$ de cará $(2,6247)$, respectivamente (Tabela 3 ). 
C. M. Vieira et al.

Tabela 1. Composição nutritiva dos componentes de quatro rações utilizadas para frangos de corte. Dourados, UFMS, 1997.

\begin{tabular}{|c|c|c|c|c|c|}
\hline \multirow{2}{*}{$\begin{array}{c}\text { Composição } \\
\text { Nutritiva }\end{array}$} & \multicolumn{2}{|c|}{ Ração concentrada $^{1}$} & \multirow[b]{2}{*}{ Milho $^{2}$} & \multirow[b]{2}{*}{$\mathbf{R M S}^{2,3}$} & \multirow[b]{2}{*}{ RTC $^{2,4}$} \\
\hline & Inicial & Final & & & \\
\hline Umidade e voláteis $\left(\mathrm{a} ~ 105^{\circ} \mathrm{C}\right) \% \mathrm{p} / \mathrm{p}$ & 12,00 & 13,00 & 11,36 & 10,89 & 10,56 \\
\hline Resíduo mineral fixo(\% p/p) & 16,50 & 16,50 & 4,65 & 8,44 & 5,52 \\
\hline Extrato etéreo(\%) p/p) & 1,50 & 1,50 & 4,24 & 0,80 & 0,71 \\
\hline Proteínas $(\mathrm{N}$ x 6,25)(\% p/p) & 41,00 & 41,00 & 8,28 & 10,52 & 9,04 \\
\hline Amido(\% p/p) & 21,26 & 19,76 & 52,32 & 53,90 & 51,59 \\
\hline Fibra $($ por diferença $)(\%$ p/p) & 7,00 & 7,50 & 19,15 & 15,45 & 22,58 \\
\hline Valor calórico totalKcal/100 g & - & - & 280,56 & 264,92 & 248,91 \\
\hline Cálcio & 6,50 & 6,50 & - & - & - \\
\hline Fósforo & 0,90 & 0,90 & - & - & - \\
\hline
\end{tabular}

${ }^{1}$.Dados apresentados pela Indústria AVIPAL- Avicultura Paranaense Ltda.

${ }^{2}$.Dados determinados no Laboratório de Tecnologia de Alimentos da UFMS, em Campo Grande - MS

${ }^{3}$.Resíduos de mandioquinha-salsa.

${ }^{4}$.Rizomas e tubérculos de cará.

Tabela 2. Peso de frangos de corte alimentados com quatro tipos de ração aos 42 dias após o início do tratamento, segundo a forma de apresentação. Dourados, UFMS, 1997.

\begin{tabular}{lccccc}
\hline \multirow{2}{*}{$\begin{array}{c}\text { Tratamento } \\
\text { (Ração) }\end{array}$} & Com penas & Sem penas & Limpo & Cozido & Assado \\
\cline { 2 - 6 } 1. Normal & $2.022,7$ & $1.907,00$ & $1.467,27$ & 943,60 & 691,23 \\
2. 15\% RTC & $1.866,6$ & $1.725,30$ & $1.300,27$ & 897,58 & 613,21 \\
3. $15 \%$ RMS & $2.113,7$ & $1.978,42$ & $1.474,31$ & $1.018,16$ & 741,72 \\
4. 30\% RTC & $1.711,0$ & $1.608,17$ & $1.198,73$ & 837,75 & 640,24 \\
\hline
\end{tabular}

RTC = rizomas e tubérculos de cará.

$\mathrm{RMS}=$ resíduo de mandioquinha-salsa.

Tabela 3. Custo de produção do frango com pena, sem pena e limpo em função do tipo de ração utilizada na alimentação. Dourados, UFMS, 1997.

\begin{tabular}{lccccccc}
\hline & \multicolumn{3}{c}{ Frango com pena $^{1}$} & \multicolumn{2}{c}{ Frango sem pena } & \multicolumn{2}{c}{ Frango limpo } \\
\cline { 2 - 8 } Tratamento & Peso (kg) & $\begin{array}{c}\text { Conversão } \\
\text { alimentar }^{2 /}\end{array}$ & Custo (R\$) & Relação 1* & Custo (R\$) & Relação 2** & Custo (R\$) \\
\hline 1. Normal' & 2,0227 & 2,1646 & 0,5473 & 1,0607 & 0,5805 & 1,3785 & 0,7545 \\
2. 15\% RTC & 1,8666 & 2,3246 & 0,5059 & 1,0819 & 0,5473 & 1,4355 & 0,7262 \\
3. 15\% RMS & 2,1137 & 2,1186 & 0,5083 & 1,0684 & 0,5431 & 1,4337 & 0,7287 \\
4. 30\% RTC & 1,7110 & 2,6247 & 0,4855 & 1,0639 & 0,5165 & 1,4273 & 0,6930 \\
\hline
\end{tabular}

* Relação 1. Peso frango com pena/peso frango sem pena.

** Relação 2. peso frango com pena/peso frango limpo.

1/ Aos 42 dias de idade das aves.

$2 / \mathrm{kg}$ de ração consumida/kg de frango com penas

3/ Ração normal com a composição de $30 \%$ de ração concentrada $+70 \%$ de milho. 
Esse fato poderia relacionar-se à maior quantidade de resíduo mineral fixo, proteínas e amido da ração com $15 \%$ de mandioquinha-salsa, em relação aos outros tipos de ração utilizados no experimento (Tabela 1). Os menores custos de produção $/ \mathrm{kg}$ de frango com pena (R\$ 0,2405), sem pena ( $\mathrm{R} \$ 0,2745)$ e limpo ( $R \$ 0,4943)$ foram dos frangos alimentados com ração contendo resíduos de mandioquinha-salsa e os maiores custos corresponderam aos frangos alimentados com ração contendo $30 \%$ de cará (Tabela 3).

A maior quantidade de cada frango limpo comercializada e realmente consumida - cozida $(1.018,16 \mathrm{~g})$ ou assada $(741,72 \mathrm{~g})$ - correspondeu ao frango criado com ração que continha mandioquinha-salsa (Tabela 2), com custo/kg de frango de $\mathrm{R} \$ 0,7158$ e $\mathrm{R} \$$ 0,9825 , respectivamente. Ao comparar qualitativamente o sabor e o teor de gordura, foi observado que os frangos ali- mentados com ração com resíduos de mandioquinha-salsa ou, especialmente, com cará apresentaram sabor de frango "caipira" e mínimo teor de gordura, possivelmente pelos baixos conteúdos de extrato etéreo e de poder calórico das matérias secas dessas hortaliças (Tabela 1). Essas características possibilitam o oferecimento de frangos tipo "light" a menores preços, no caso dos frangos alimentados com ração contendo mandioquinha-salsa (Tabela 3 ), os quais

Tabela 4. Produção e custos de produção dos componentes, além da relação percentual de custos das fórmulas das rações para frangos de corte. Dourados, UFMS, 1997.

\begin{tabular}{|c|c|c|c|c|c|}
\hline \multirow{2}{*}{ Produto } & & \multirow[b]{2}{*}{$\begin{array}{c}\text { Produção } \\
\text { (kg/ha) }\end{array}$} & \multicolumn{3}{|c|}{ Custo de produção $(\mathbf{R} \$)$} \\
\hline & & & Total & $\begin{array}{c}\begin{array}{c}\text { Matéria fresca } \\
\text { comercializável } \\
(\mathrm{kg})\end{array} \\
\end{array}$ & $\begin{array}{l}\text { Matéria seca } \\
(\mathrm{kg})\end{array}$ \\
\hline \multicolumn{2}{|c|}{ Milho Embrapa } & 6.000 & 536,80 & 0,0895 & 0,11 \\
\hline \multicolumn{2}{|c|}{ Milho (média em MS) } & 3.500 & 636,80 & 0,1534 & 0,11 \\
\hline \multicolumn{6}{|c|}{ Mandioquinha-salsa } \\
\hline \multicolumn{2}{|c|}{. Raízes } & 13.200 & $1.374,45$ & 0,104 & \\
\hline \multicolumn{2}{|l|}{ Resíduos } & 30.800 & 200,00 & & 0,0325 \\
\hline \multicolumn{2}{|c|}{$\begin{array}{l}\text { (folhas, rebentos, raízes não-comercializáveis e } \\
\text { coroas) }\end{array}$} & $(6.160)$ & & & \\
\hline \multicolumn{6}{|c|}{ Cará } \\
\hline \multicolumn{2}{|c|}{. Tubérculos } & 19.200 & $1.146,36$ & 0,06 & \\
\hline \multicolumn{2}{|c|}{ Resíduos } & 18.600 & 200,00 & & 0,0538 \\
\hline \multicolumn{2}{|c|}{ (tubérculos pequenos, refugos e rizomas) } & $(3.720)$ & (Industria-lização) & & \\
\hline \multicolumn{2}{|l|}{ Ração } & \multirow[b]{2}{*}{ Fórmula \% } & \multicolumn{3}{|c|}{ Custo $(\mathbf{R} \$ / \mathbf{k g})$} \\
\hline Número & Componente & & Componente & Fórmula & $\begin{array}{c}\text { Relação } \\
\text { percentual }\end{array}$ \\
\hline \multirow[t]{3}{*}{1} & Concentrado & 30 & 0,1600 & 0,048 & \\
\hline & Milho & 70 & 0,1100 & 0,077 & 1,00 \\
\hline & & & & 0,125 & \\
\hline \multirow[t]{4}{*}{2} & Concentrado & 30 & 0,1600 & 0,0480 & \\
\hline & Milho & 55 & 0,1100 & 0,0605 & 0,9328 \\
\hline & Cará & 15 & 0,0538 & 0,0081 & $(-6,72)$ \\
\hline & & & & 0,1166 & \\
\hline \multirow[t]{4}{*}{3} & Concentrado & 30 & 0,1600 & 0,0480 & \\
\hline & Milho & 55 & 0,1100 & 0,0605 & 0,9080 \\
\hline & Mandioquinha-salsa & 15 & 0,0325 & 0,0050 & \\
\hline & & & & 0,1135 & $(-9,20)$ \\
\hline \multirow[t]{4}{*}{4} & Concentrado & 30 & 0,1600 & 0,0480 & \\
\hline & Milho & 40 & 0,1100 & 0,0440 & 0,8648 \\
\hline & Cará & 30 & 0,0538 & 0,0161 & \\
\hline & & & & 0,1081 & $(-13,52)$ \\
\hline
\end{tabular}


poderiam ser utilizados para exportar a países europeus e Estados Unidos, onde há grande consumo de frangos de corte e sérios problemas com alimentos gordurosos (Fantástico da Rede Globo, 7 de julho de 1997). Os frangos alimentados com ração normal mostraram-se excessivamente gordurosos, provavelmente devido ao maior teor de extrato etéreo $(4,24 \%$ e/ou do valor calórico do milho utilizado na ração (Tabela 1). Esse fato demonstra o grande potencial de uso de mandioquinha-salsa e a possibilidade de maiores lucros para o avicultor e para o agricultor, que poderá vender normalmente as raízes, para consumo ao natural ou processado, assim como utilizar os resíduos da planta para composição de rações para frangos de corte (Tabela 4). Isso porque o custo da matéria seca dos resíduos $(\mathrm{R} \$ 0,0325)$ re- presentariam $29,55 \%$ em relação ao custo do milho $(\mathrm{R} \$ 0,11)$ e que após seu uso percentual no formulado da ração induziria diminuição de $9,20 \%$ no custo.

\section{LITERATURA CITADA}

CEREDA, M. F. Valorização de resíduos como forma de reduzir custos de produção. In: CONGRESSO LATINO AMERICANO DE RAÍZES TROPICAIS, 1, CONGRESSO BRASILEIRO DE MANDIOCA, 9. São Pedro - SP. Palestras-painéis-mesas redondas. São Pedro, CERAT, p. 25 - 43, 1996.

ENGLERT, S. Avicultura: tudo sobre raças, manejo e alimentação. Guaíba: Agropecuária, 1998. $238 \mathrm{p}$.

HEREDIA Z., N. A.; VIEIRA, M. C. Produção de dois clones de cará (Dioscorea $\mathrm{sp}$ ), considerando três populações, em Dourados MS. SOBInforma, Curitiba, v. 13, n. 2, p. 24 - 26, 1994.

HEREDIA Z., N. A.; VIEIRA, M. C.; RIBEIRO, R. A. Perdas de peso pós-colheita de rizomas e de tubérculos de cará (Dioscorea sp) em Dourados - MS. SOBInforma, Curitiba, v. 14, n. 1/2, p. $22-24,1995$.
HEREDIA Z., N. A.; YAMAGUTI, C. Y. Curvas de crescimento de cinco clones de inhame, em solo "sempre úmido", considerando épocas de colheita, em Dourados - MS. SOBInforma, Curitiba, v. 13, n. 2, p. 23 - 24, 1994.

SILVA, J. R. B. da. Mandioca e outras raízes tropicais: uma base alimentar da humanidade no século XXI. In: CONGRESSO LATINO AMERICANO DE RAÍZES TROPICAIS, 1, CONGRESSO BRASILEIRO DE MANDIOCA, 9. São Pedro - SP. Palestras-painéis-mesas redondas. São Pedro, CERAT, p. $12-15,1996$.

SCHMIDT, G. S.; ÁVILA, V. S. de. Linhagens avícolas brasileiras. In: SOCIEDADE BRASILEIRA DE ZOOTECNIA (eds). Avicultura. Piracicaba: FEALQ, p. 31 - 36, 1990.

VIEIRA, M. C. Avaliação do crescimento e da produção de clones e efeito de resíduo orgânico e de fósforo em mandioquinha-salsa no Estado de Mato Grosso do Sul. Viçosa: UFV, 1995. 146 p. (Tese doutorado). 